\title{
Use of a Model for Information Technology Education
}

\author{
Peter Trkman and Peter Baloh \\ Faculty of Economics, University of Ljubljana, Ljubljana, Slovenia
}

\section{peter.trkman@uni-lj.si peter.baloh@uni-lj.si \\ Executive Summary}

This paper presents a newly developed theoretical model for planning and evaluation of educational process at all levels of education. Special attention is paid to education at the university level. The main purpose of the model is to help an instructor maximize the final value of education as perceived by students.

The main concept of the model is based on broader understanding of this process, taking into account not only education itself and the knowledge gained in it, but also the impact on efficiency of later learning and the degree of usefulness of knowledge. Thus, we claim that the main goal of educational process is to maximize the total useful knowledge and not the quantity of knowledge gained in the process itself. We identify four main components of the model as: degree of usefulness of total knowledge, total knowledge itself, reduction of effort in later learning and the effort invested in the process by a student.

Besides the sole quantity of gained knowledge $\left(1^{\text {st }}\right.$ subgoal $)$ special attention should be paid to the fact that acquired skills and knowledge gained are also useful and applicable to problems, encountered by students in the course of their professional careers ( $2^{\text {nd }}$ subgoal). Another important aspect is to equip students with necessary skills to make their later education easier ( $3^{\text {rd }}$ subgoal). Although learning obviously requires substantial effort from a student, special attention should be paid to the decrease of this effort or at least to its unnecessary increase ( $4^{\text {th }}$ subgoal). These subgoals should be achieved in any type of education, while the importance of each single goal is different on different levels of education.

Theoretical findings of the model are then applied to computer science education at the undergraduate level. Firstly, the fundamental objective of computer science education is identified, to qualify undergraduate students for efficient use of contemporary IT tools in their upcoming student and professional careers. Secondly, we illustrate how each of the four main model subgoals can be influenced in order to maximize the utility of the educational process for students. Furthermore, we explain how integrating various levels of education (primary, secondary schools, universities...) can bring substantial benefits and how the priority shifts between different subgoals at different levels of education.

At last, application of the model is shown on a case study of teaching information technology lab lectures for undergraduate business students at the University of Ljubljana, Faculty of Economics, where both authors have worked in recent years. Due to time constraint and limited resources it is vital that no

\footnotetext{
Material published as part of this journal, either on-line or in print, is copyrighted by the publisher of the Journal of Information Technology Education. Permission to make digital or paper copy of part or all of these works for personal or classroom use is granted without fee provided that the copies are not made or distributed for profit or commercial advantage AND that copies 1) bear this notice in full and 2) give the full citation on the first page. It is permissible to abstract these works so long as credit is given. To copy in all other cases or to republish or to post on a server or to redistribute to lists requires specific permission and payment of a fee. Contact Editor@ JITE.org to request redistribution permission.
} major mistakes are made in planning those lectures.

Changes and improvements in recent years that were made on the basis of model assumptions are presented. Those improvements include studyingby-real-case-solving, partial dispensation of students by their entry-level-knowledge and strong connections with other courses at the faculty. Students' satisfaction is continuously measured 
by different surveys. Survey results, presented in the paper, show that in general students believe that most of the subgoals are sufficiently achieved.

Keywords: information technology, IT education, pedagogic model, university education

\section{Introduction}

In recent years, plenty has been written about the importance of education and several different models have been proposed for planning, organization and evaluation of the educational process. The main contribution of this paper is to provide a general theoretical framework that can be used for planning and evaluation of various sorts of education at different levels. The model emphasizes the importance of a student and of his or her goals in education and identifies four main sub goals from the student's point of view that should be fulfilled in every organized learning. As shown in the next sections, the advantage of the model lies in the fact that it can be easily adapted if needed, according to specific characteristics or demands of different ways of education. In this paper, the model has been tailored to computer literacy education at the undergraduate university level.

The paper is organized as follows: in the first section a few words are devoted to education itself. Next, the model for planning and evaluation of educational process, which formalizes a process of life-long learning, is presented and explained. Then the model is applied to computer literacy education in general and specifically to computer literacy education and its role in higher education. At the end practical improvements that can be made following the model guidelines are shown with a case study of computer labs for first year undergraduate business students at the Faculty of Economics, University of Ljubljana, where both authors have worked in recent years.

\section{About Education}

Each instructor uses his or her own approach to teaching and instructing, which he or she believes is the best for the students. Unfortunately, many educators seem unaware of the abundance of the research literature in the teaching and learning sciences to support and question their teaching approaches (Collis, 1998). Key principles for university didactics, as comprehensively reviewed and summarized (Collis, 1998) are:

- Learning arises from the active engagement of the learner; cognitively active roles of both instructor and learner are necessary (Moonen, 1994).

- Communication oriented pedagogy is turned towards the learner; assessment of competence depends on listening, observing and responding to learners.

- Good learning is not instructor-transmission oriented but rather process-based and learner oriented.

- A well-designed instructional environment requires instructor preparation, yet it is aimed at learner self-responsibility (Luft \& Tiene, 1997).

- "We must do more with less;" students want to move efficiently through their studies, instructors have to move efficiently through their budget (McAvinia \& Oliver, 2002).

A common compass reading behind the me ntioned principles can be recognized: some sort of strategic orientation in knowledge and skills that the educational system has to provide to a student. Though, not by pushing but rather by preparing learners to pull knowledge and by endowing them with skills that will enable and ease their further education.

Candy (2000) argues that since organizations are becoming more knowledge-based, academics as knowledge workers are ideally equipped to help students become lifelong learners in the information society. He suggests that: 
"Universities have a leadership role in producing graduates who are [. . .] attuned to the need for, and equipped with the skills of, continuing lifelong personal and professional development." (Candy, 2000, p. 275)

Similarly and in connection with the topic, Director of the Information Centre of the International Association of Universities, has indicated:

"The future of universities depends on the capability to adapt to the new information society and meet the needs of an ever more demanding professional market..." (Langlois, 1997, p. 7 as cited in Collis, 1998, p. 374)

The importance of the educational system for young people cannot be overemphasized. To sum up in plain words: what students learn has to be useful, and they have to learn it in the way that they learn also how they will be able to gain new knowledge without too much trauma and unnecessary efforts.

\section{Presentation of the Model}

As outlined in the previous section, education is extremely important and its importance is increasing even further. Therefore, careful planning and evaluation of every organized education is essential. The purpose of the model presented in the paper is to offer a comprehensive framework for evaluating every educational activity. The starting point for the planning and evaluation of education is a student's point of view - his or her needs and expectations from education where he or she is taking part. The following model can serve as general set of guidelines. Its schema is presented in Figure 1 and it is explained in the continuation of the paper.

The meaning of the abbreviations in Figure 1 are as follows:

- $K_{i}$ - input knowledge-Student's knowledge at the beginning of the process.

- $E_{1}$ - effort-Student's effort invested during the process.

- $K_{o}$ - output knowledge - Knowledge at the end of the process.

- $\quad E_{2}$ - effort in later (lifelong) learning with this process - If our educational efforts are successful they should also help the students gain new knowledge easier - thus reducing the effort in later education.

- $K_{u}$ - total useful knowledge - Obviously not all knowledge is useful for each individual. Therefore, this variable measures only the useful knowledge - the knowledge that can be applied or can help in life or at work.

- $\quad K_{f}$ - total final knowledge - Total knowledge gained by a student.

- a - share of total knowledge that is useful for each individual.

Also needed for our purpose (and not shown in Figure 1 yet described below and used later in the model) are two additional variables:

- $\quad E_{2}^{\prime}$ - effort in later (lifelong) learning without this educational process.

- $\quad K_{u}{ }^{\prime}$ - total useful knowledge without this educational process.

Traditionally, it would be assumed that the goal is to maximize the amount of knowledge gained by the students in the process (that is to maximize $\mathrm{K}_{\mathrm{o}}-\mathrm{K}_{\mathrm{i}}$ ). This can be achieved and measured relatively easily with various simple tests at the end of the educational process. However, in the constantly changing environment and the concept of lifelong learning gaining more and more importance, this is an assumption we should not make. The educational process concentrated solely on the amount of knowledge gained is missing important parts of the big picture. 

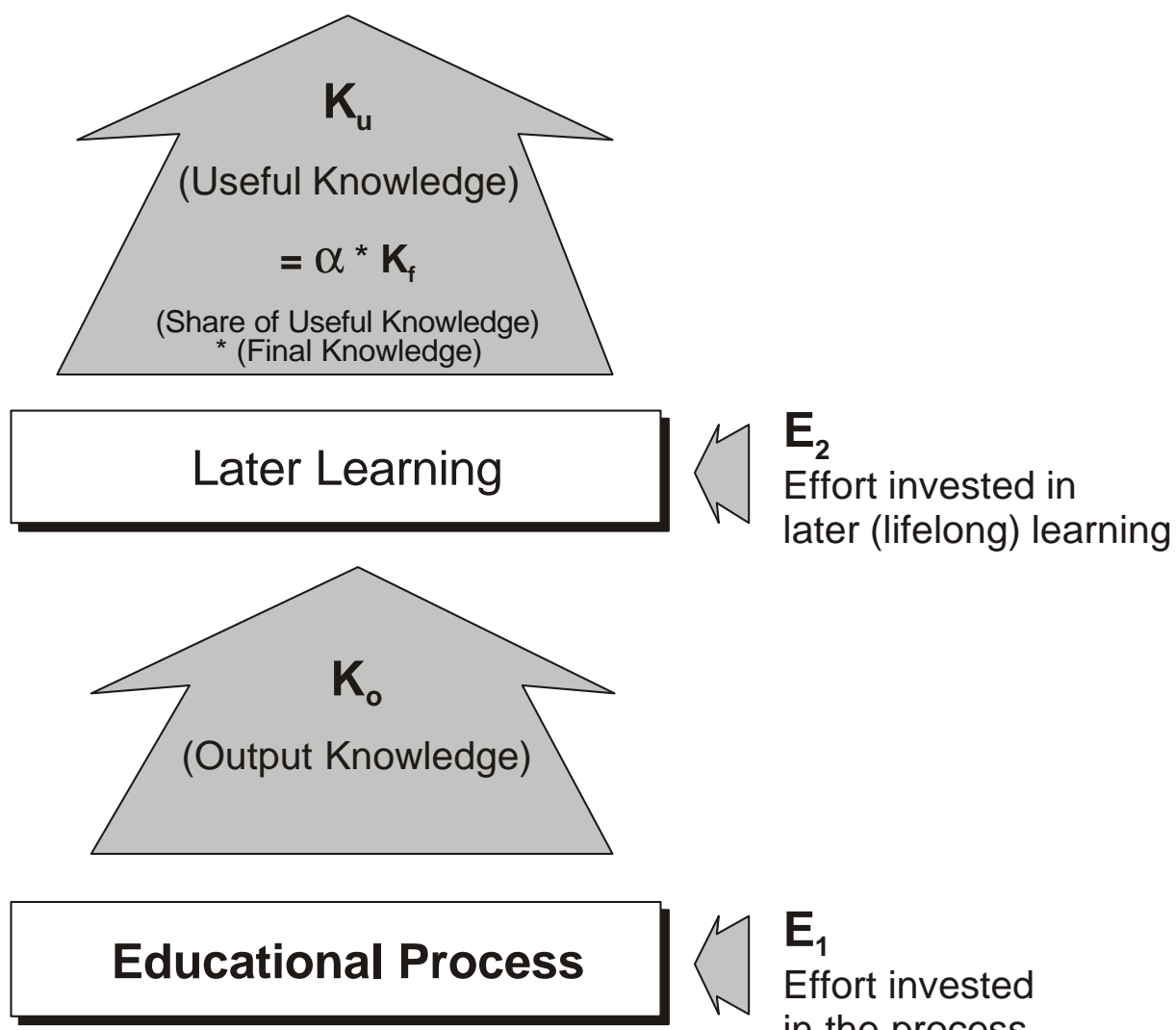

$\mathbf{E}_{1}$
Effort invested
in the process

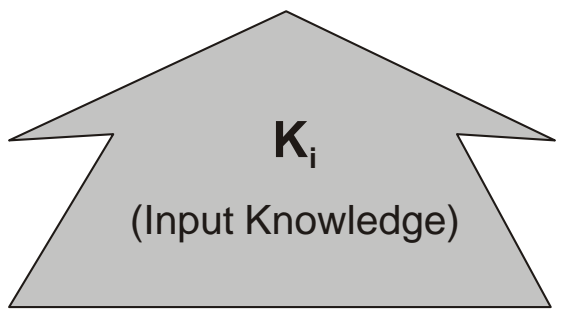

\section{Figure 1: The scheme of the model}

Therefore, we need to take broader situation into account. The proposed model based on Figure 1 can be written as: the main goal of the educational process is to maximize the difference between the benefits of the education and its costs.

This means that we need to maximize the sum of the product between useful and total knowledge and reduced effort in later education minus the effort that needs to be invested in the process. This can be written as:

$$
\max \left(\left(\mathrm{K}_{\mathrm{u}}-\mathrm{K}_{\mathrm{u}}{ }^{\prime}\right)+\left(\mathrm{E}_{2}{ }^{\prime}-\mathrm{E}_{2}\right)-\mathrm{E}_{1}\right)=\max \left(\mathrm{a}^{*} \mathrm{~K}_{\mathrm{f}}-\mathrm{K}_{\mathrm{u}}{ }^{\prime}+\left(\mathrm{E}_{2}{ }^{\prime}-\mathrm{E}_{2}\right)-\mathrm{E}_{1}\right)
$$

As total useful knowledge without our educational process $\left(\mathrm{K}_{\mathrm{u}}{ }^{\prime}\right)$ is given (from our viewpoint), this parameter in the equation can be ignored and the final equation is:

$$
\max \left(\mathbf{a}^{*} \mathbf{K}_{\mathbf{f}}+\left(\mathbf{E}_{\mathbf{2}}{ }^{\prime}-\mathbf{E}_{\mathbf{2}}\right)-\mathbf{E}_{\mathbf{1}}\right)
$$

The idea of the model is to serve as a framework when considering possible changes in education and not to calculate a single number that would reflect total benefits of the process. Therefore, a simple addition and subtraction formula is chosen instead of a more complex way of presenting this model (e. $\mathrm{g}$. exponential). 
Four sub goals can be derived from the main goal:

1. Maximize the total final knowledge of students $\left(\mathrm{K}_{\mathrm{f}}\right)$

2. Maximize the share of useful final knowledge (a)

3. Maximize the difference between $\left(\mathrm{E}_{2}{ }^{\prime}-\mathrm{E}_{2}\right)$

4. Minimize the effort needed in the educational process by the students $\left(\mathrm{E}_{1}\right)$

This division can improve the approach to both planning and evaluation of educational effort. However, it should not be forgotten that those sub goals are usually interconnected. Typically, we need to obtain all four goals in order to claim that education was successful. The priority shifts between the sub goals in dependence on various factors (e.g. the level of education, topics of the course, students' characteristics such as age, interests and so forth) - an example on how the priorities are different on different levels is shown in the section about computer literacy education.

The four sub goals are further explained:

1. Maximize the total final knowledge of students. Students should learn as much as possible; this is a clear sub goal as, after all, one of the roles we concentrate on in the presented model is how to teach students something (or even better to help them learn it themselves). Significance of knowledge in today's world has already been extensively discussed (Bell, 1973; Burton-Jones, 2001;Drucker, 2001; and Johannessen, Olaisen, \& Olsen, 2001, to name only a few), so every bit of knowledge that can be gained is important.

However, the main difference between this model and traditional education is that maximization of total final knowledge is only one of the 4 sub goals and not necessarily the most important one. Quite the opposite; in fact, other sub goals contribute to importance. Therefore, the amount of total knowledge gained by the students is not adequate proof to claim that teaching was successful.

2. Maximize the share of useful final knowledge. As knowledge is becoming obsolete faster than ever before, it is obvious that even a perfectly designed and executed curriculum certainly has some topics that will not be useful for most of the students. Due to diversity of students in every group it is hard to offer only useful and interesting things to each individual, although the World Wide Web can certainly help in adjusting the program in such a way that it is more appropriate for each individual (McIntyre, \& Wolff, 1998; Trkman, \& Baloh, 2002b]). In addition, it is quite hard to predict which skills the employers will likely need in the future (Drew, 1998; McAvinia, \& Oliver, 2002).

However, all this should not be used as an excuse not to continuously adjust the educational program in such a way to offer useful and relevant topics to these diversified groups of students and each individual. Therefore, special attention has to be paid to teaching the matters that students will need and in such a way that the usefulness of gained knowledge is transparent to them, even to those who would otherwise classify themselves as "totally uninterested."

3. Maximize the difference between $\left(\boldsymbol{E}_{2}{ }^{\prime}-\boldsymbol{E}_{2}\right)$. This can be explained as, "teach the students to learn." With the importance of life-long learning ever increasing, it is clear that it is impossible to teach students everything they need to know within the given course regardless of the subject, level of education, available time and funds. As stated before, everyone will have to invest significant time, effort and resources in formal and informal ways of education later in his or her life. Therefore, we need to make everything possible to help him or her ease the effort needed in later education.

This important component is expressed in the model as a difference between the efforts that students will need to invest in later education after visiting the course $\left(\mathrm{E}_{2}\right)$ and the effort that would be needed if they had not attended our course $\left(\mathrm{E}_{2}^{\prime}\right)$. If we were successful in attaining this goal, the effort needed later should be considerably reduced. 
Use of a Model for IT Education

Discussed subgoals are obviously important for practical implementation of the model. The question is, how to measure in what extent each of the subgoals has been achieved. At present stage of research, the model is still formulated in conceptual form, requiring refinement of instruments for measuring the achievement of some of the sub goals.

The idea of this sub goal can be further explained with the following quotation:

"Traditional training methods are appropriate for teaching people what to think ... If they are to get the most out of information technologies, people also need to learn how to think. Learning how to think means developing the intellective skill required for original, independent problem-solving." (Schuck, 1996, p. 205 as cited in Candy, 2000, p. 270).

This sub goal has already been widely acknowledged as one of the most important goals in every education. Therefore, one of the vital aspects of every education is to empower learners to develop their own skills of observation, enquiry, interpretation, not just to transmit authoritative expert knowledge (Hawkey, 2002). Surely today's educators can deliver to students a knowledge in how to redirect useful methods learned that will not be wasted by becoming obsolete but rather be redeveloped in a recycling and updating fashion.

If we manage to do this we certainly made a large step towards achieving the third sub goal of the model; a student that develops the mentioned skills will certainly find it easier to acquire new knowledge and, even more importantly, use it productively. Then future education is definitely easier.

4. Minimize the effort needed in the educational process by the students. This is one of the sub goals that is often neglected or considered less important. Nevertheless, we do not want to claim that education is possible without student's involvement or effort. The invested effort can be measured with the sum of opportunity and actual costs incurred by the students. Both types of costs are understood broadly. The actual costs, for example, include costs such as scholarships, study materials (books, computers, etc.), and the cost of transportation, and lodging (These costs can also be considerably reduced by using the World Wide Web). On the other hand, although opportunity costs can be high for the students, it is obvious that those costs increase greatly once the students start their working careers, as every day of absence from work place is rather expensive for their employers. Consequently, as many skills as possible (especially the ability to learn new things quicker) should be obtained as early as possible.

Besides the economic aspect (total costs of education), effort (as perceived by students) can be quite subjective and depends on their attitude towards the course. The learning is certainly considerably easier if students see the usefulness and applicability of lessons learnt. Therefore achievement of the second sub goal is not enough. The usefulness of gained knowledge should also be made clear to the students, so in that way we also move closer to the achievement of the fourth goal.

It is an undeniable fact that any learning requires effort; we only claim that the goals should be reached as easy as possible without making it unnecessarily difficult.

Every change or improvement in the education can be explained within this framework as it affects at least one of the four the sub goals. The change in the education that does not do so is most likely useless.

The proposed model is deliberately set quite broad so it can be used for various sorts of education and in various fields of science. Other educational models can also be included and explained with the previously defined four sub goals of our model. For example, one of the models proposed by Bradley and Oliver (2002) has the following guidelines:

- Open learning $(\mathrm{OL})$ - the learning should take place at the time and place of the learner's choosing;

- Computer based learning (CBL) — the learning should be delivered through a computer system; 
- Work based learning (WBL) — the learning should be applicable to and developed within a working environment.

The first guideline can be explained with the $4^{\text {th }}$ sub goal; if we manage to enable a learner to choose his time and place for the learning process that certainly considerably decreases the effort needed and the costs incurred. Work based learning can considerably influence both the $2^{\text {nd }}$ and the $4^{\text {th }}$ sub goal as the learning that is applicable to work environment increases the percentage of gained knowledge that is useful and on the other hand decreases the effort needed as the learning problems are directly connected with work and therefore for students easier to comprehend and solve.

The model presented in this section can serve as a guideline for any education; in the following section we apply it to the field of computer literacy education in general and expressly to computer literacy education at the university level.

\section{Computer Literacy Education}

Computer literacy is one of the most important skills a person can have in today's competitive environment. One of the most important changes was the transformation of blue-collar workers into white-collar workers (Kaplan, \& Norton, 1996, as cited in Hughes, Ginnett, \& Curphy, 1999). Employees today must contribute value by what they know and by the information they can provide. Following that, it is harder and harder to imagine a successful professional career without decent knowledge of information technology (IT) and its effectual use.

Accordingly, one of the important tasks the school system has to fulfill is to empower students for effective use of technological tools in their future and present daily work.

There are some issues and constraints that need to be taken into account, though. Firstly, distinctions in students' interests cause the entry level of IT knowledge, when enrolling in any educational institution, regardless of the level, to vary significantly. Additionally, in the case of university level, students greatly differ in their backgrounds; they come from technical-, natural- and social-science oriented secondary schools.

Secondly, attitudes and interests of students and the way in which they accept computer labs vary from interested to uninterested.

Thirdly, both students and instructors (or universities as institutions) work within their budgets. As already said, "we must do more with less." On the learners' side it means that students are aware that their time and energy is a scarce resource and they want to rationalize the way they move through their studies (Collis, 1998). On the side of lecturers, it means that they cannot afford to instruct each of their students individually and "forever." There is a time constraint (in non-technical university programs, the time "budget" for computer labs is usually very limited) and often shortages of both properly qualified instructors and properly equipped classrooms.

Fourthly, there is an additional problem that we face in the field of computer literacy education. As it is known, "experience leads to habitual behavior patterns" (Hughes, Ginnett, \& Curphy, 1999). Following that and applied to instructing of use of information technology, we have recognized that students misapply old solutions to new problems. That is, since they are not aware of extensive functionalities of modern IT tools, they indeed use them "in old ways"; only the (already) known portion of certain applications are consequently used in most cases. Of course, problems that students are faced with (for the period of their studies and during real jobs) are often solved in numerous different ways, mostly inefficient and ineffective ones. For example, instead of using the "filter" tool in spreadsheets (which returns required information from a table of data in hassle-free manner), combinations of various known tools, such as the "sort" tool, and manual data-manipulation (manual checking) are used. 
The natural conclusion and solution to this problem is to (1) challenge students with real-life cases and problems they are most likely going to encounter in the near future, and (2) present them with a way to solve a certain case (using an appropriate application).

Fifthly, the issue of the main goal of the computer labs has to be resolved. In times of perpetual changes, something learned today not only "might not be" but rather "will not be" usable tomorrow in the same form as today. Today's students will have to deal with many new software and hardware solutions for a variety of problems during the span of the next thirty or forty years. Most of those solutions are not even known today. Therefore, in computer literacy education, of the four sub goals mentioned in the previous section, the third should be emphasized. Consequently, in the example it does not make much sense to show the students only how to accomplish a certain task in one of the applications with a series of mouse clicks and keyboard commands and leave them with that. Rather, students have to learn how to learn in order to survive in the "jungle" of upcoming software and hardware. The objective of the educational process has to be to qualify students to be able to learn independently and continuously. This also coincides with the lifelong learning mentioned in the introduction. That means that the amount of useful knowledge they gain from the computer labs is important. Namely, the central goal is to prepare the students for effectual use of information technology for dealing with problems and challenges they will face in their upcoming student and professional careers.

In order to achieve this we put forward the following system of computer literacy education at various levels of education. From this system, it is also understandable how the emphasis shifts between sub goals at different levels:

- Kindergarten and lower grades of primary school: special emphasis should be paid to subgoals 3 and 4. Subgoal 4 is important because if too much effort to learn the use of computers is needed by the children at this level, it might negatively influence the children's attitude towards computers and information technology, which can importantly influence the success of later education. At the end of this educational level, children should not be afraid to use computers and be able to perform basic tasks.

- Higher grades of primary school: pupils should be familiar with the use of computers and should be aware of common applications and their purpose, i.e. operating systems, word processors, spreadsheets, database management systems, Internet browsers and so forth. As a result, they should be able to perform general tasks related to file management, formatting, inserting pictures in documents, browsing the Internet, and so on.

- Secondary school: at the end of this level, students are computer-literate: they should be able to confidently use the most widely spread applications for various general and specific tasks, i.e. creating a document with headers \& footers, inserting table of content, working with page numbering; creating a presentation and performing it and using the Internet to find certain information.

- University level: in an ideal world, students bring computer literacy from prior educational levels. At the undergraduate level they acquire expertise in the use of common and specific applications for solving problems that would most probably occur later in their future life and professional career.

- The content of the lab lectures and the examples discussed naturally depend on the field of study program. Therefore, instructions for business students need to put special emphasis on solving problems (naturally using contemporary IT tools) in business and economics.

- Similarly, the British and Irish Legal Education Technology Association (1994) offered "common minimum standards of computer competency for undergraduate law students", which were divided into three contextual parts: (1) Common knowledge of information technology, (2) In- 
formation technology for lawyers, and (3) Law of information technology. The first one deals with basic computer skills, such as operation system, file and disk management, word-

processing, use of e-mail, spreadsheets and databases, all at general level and of generic use. The second and the third deal with specific, law-oriented needs. As we argued above, our opinion is that the first level - common knowledge of IT - has to be taught at lower levels of education, not at university. Undergraduate level should focus on special needs that each student will need in his future career.

- Workplace learning: there, evidently, the most important subgoal is the goal no. 2; the gained knowledge should be directly applicable to the problems encountered by the employees in the workplace. When instructing professionally active students, practical examples taken from the workplace should be solved in a pragmatic manner, in teams or independently. Essentially, learning here comes from the active engagement of the learner.

Of course, only when horizontal and vertical integration and coordination between educational levels are achieved, can the fulfillment of the goals set for computer literacy education be expected. A national (maybe even worldwide) scheme should be developed and followed; some have already started: in Slovenia a program for Computer Literacy has began in primary schools (Rajkovic, 1998); worldwide, the European Computer Driving License (ttp://www.ecdl.com) has been promoting a "computer license" for the last couple of years.

Arguably, without extensive coordination of vertical levels of education, the goals are more difficult to reach. Also, vertical and horizontal harmonization brings additional benefits, such as set standards that assure working conditions for educational institutions and overall higher quality of the educational system (Schuck, 1996).

\section{Case Study: Faculty of Economics, Ljubljana}

In order to show how the proposed model and guidelines for implementation of the model for computer literacy education can be used in practice, the case study of computer lab lectures at the University of Ljubljana, Faculty of Economics, is presented.

Here are offered mainly the changes and improvements that were made following the model guidelines. A more detailed presentation of this case study can be found in Baloh and Trkman (2002) and Trkman and Baloh (2002a).

The Faculty was established in 1946 and the number of students has grown ever since. In the last decade, approximately 600 students enroll into the University study program yearly and 400 in the Business School study program. In addition, there are approximately 800-900 first-year students in part-time and distance education programs. The background of those students varies extremely as they come from high school (around 45\%) and economics secondary schools (36\%), while only $2 \%$ finish a technical secondary school where the use of computer and information technology is most widely spread (Gerlic, 2001).

Although in previous sections the system in which students should be completely computer literate at the end of secondary school was outlined, this is not the case with these students. Partly because students that enter higher education today started their formal education at the end of the eighties or the beginning of the nineties, when the use of computers was not widely spread in primary schools.

Also the goal of secondary school system in Slovenia is to "enable students to work with any data format and to make them able to use software in different version and from various vendors” (Krapež, 1999). However as in most secondary schools there are only 70 hours (in 4 years) of computer literacy education (Krapež, Rajkovic, Batagelj, \& Wechtersbach, 2001), we are still far away from the achievement of this goal. Due to various programs and initiatives (such as Computer Literacy Program 
(Rajkovic, 1998)) the average level of computer knowledge is noticeably increasing year after year but it will certainly take years before the afore-mentioned goal will be achieved.

At the Faculty of Economics of Ljubljana, students in both programs have a course in the first year that deals with computer and business information systems concepts that will likely be needed by business students in their future careers. It is a one-term subject and is divided in two parts: "theoretical" and "practical". In this case study we deal solely with the practical part of those two courses. Due to time constraints and limited budget, there are only 1-2 hours per week left for the labs for each student. At the end of this first year this totals between 15 (University study program) and 30 hours (Business School study program). In this time students should learn how to use a computer to solve problems during their studies and later in the workplace. The main topics covered are MS Windows, MS Office applications (Word, Excel, PowerPoint and Access) and the Internet (World Wide Web and use of e-mail). As the amount of time is extremely limited (commercially available training programs usually last 30 hours just to complete one level-course in one application (i.e. introductory course to Excel)) no major mistakes should be made in utilization of the available time. However, in spite of limited time we keep our mind on each of the subgoals and try to improve the added value of all four subgoals.

As can be seen from above, there are significant issues for planning and implementing the educational process. For that reason we try to follow the model guidelines and maximize the value of the labs for our students.

In summary, the pedagogical model was developed based on certain methods for obtaining each of the mentioned main subgoals individually while meeting the limitations and problems presented earlier in the account. The resulting model is realistic and pragmatic; it is founded on the following methods:

For goal no. 1 ( "maximize the total final knowledge of students"): firstly we decided to make attendance at the computer labs compulsory. Although this was an unpopular decision at the beginning, it was soon accepted (in the survey less than $17 \%$ of the students found that inconvenient (Introduction to information systems, 2001)). At the end of the first year the knowledge of all students is tested and the result contributes towards their final grade in the course (together with the "theoretical" part), so extrinsic motivation also plays a role, although intrinsic motivation (explained in detail below) is certainly the most important.

A special attention is being paid towards proper qualification, training and prior experience of all instructors. Even an extremely well-designed program that follows all the guidelines of the model would fail miserably if the instructors were inappropriate. The success in the selection of instructors can be illustrated with the results of the survey in which students also marked their satisfaction with the work of the instructors; on the scale from 1 to 5, the average grade was 4.5, which shows that students were very satisfied with the work of instructors (Introduction to information systems, 2001).

The program of the lectures is revised each year to meet changing demands and entry-level knowledge of students; every year the level slightly increases and new topics and examples are added.

In order to offer added value to all students (even those with very high entry-level knowledge) we partially segregated our students based on their knowledge and offered special courses both for those with little knowledge (an additional introductory course to Windows/Word and Internet than can be taken beside the basic course) and for those who already know most of the things discussed in the lectures. For the latter we organized an advanced-topics course with contents like advanced use of Microsoft Excel, introductions to Visual Basic for Applications, HTML, Active Server Pages, VBScript, JavaScript and so forth. Obviously, an even more detailed segregation of the students could be useful but is not possible due to organizational, financial and other constraints.

We can argue that every first-year student gains added value (expands knowledge) in computer labs and that topics are at least to some extent adjusted to their interests and entry-level knowledge. 
For goal no. 2 ("maximize the share of useful final knowledge”): As discussed above, students gain much new knowledge in the labs. Nonetheless, we also pay special attention to the usefulness of gained knowledge. Thus, we put a special emphasis on "learning by example", by introducing solely practical problems into exercises. For first-year students such problems might be a bit distant; therefore, we also include problems that students will already be facing during their undergraduate studies. For example, we show the use of Excel for creating charts and solving financial and statistical problems that are methodically taught in other courses or the use of Word for technical preparation of their seminar assignments and graduate thesis.

We should stress that we do not teach the students to know something about software application itself, but to enable them to solve real life problems and to find a solution more easily to the problems they are not yet able to solve.

For goal no. 3 ("teach the students to learn"): as already acknowledged this is arguably the most important of the four subgoals, especially for teaching the use of computers. Academics are ideally equipped to help students to become lifelong learners (Candy, 2000).

Therefore, special attention is paid to the achievement of this goal and various approaches are used. In every lesson, a certain part of the lecture is used for independent problem solving by the students; they are confronted with a real-life problem (e.g. drawing and formatting a certain chart from the given data) and try to solve it. Obviously, the instructor is present during this and can give some tips but not the final solution to the students.

During the lecture we try to encourage students to participate actively and offer their suggestions, even if those suggestions are wrong, about a possible solution to each encountered problem. With every new problem they are usually given a certain amount of time to try to find an appropriate way to a solution themselves. Even if they do not manage to find the correct solution, this is valuable experience.

Another approach we used was to divide students into small groups of 2-3 students at the beginning of the course. Each group had to study a certain aspect of one application (usually Microsoft Word or Excel) and then prepare a part of the lesson for next week and present it to their colleagues. They should study this problem independently by using computer books, built-in Help, and so on. During the preparation phase an instructor is available to provide general guidance. This approach brought some benefits. We try to encourage students to solve problems independently and to enhance their team working and presentation skills. However, due to serious time limitation it was abandoned this year.

By presenting real problems, we are trying to accustom students to independent problem solving and to become familiar with resources they can use to help them, such as built-in Help, Internet, and reference book.

For goal no. 4 ("minimize the needed effort in the educational process by the students"): in order to minimize the effort needed by students to achieve the goals we try to make the learning process as easy as possible. Therefore, special attention is paid to keep the explanation of important things clear and to explain them entirely using practical examples.

In every class of approximately 25 students, the instructor has one assistant that helps the students who either have difficulties or additional questions that are not directly related to the subject. Additional information can also be obtained from a WWW page (See more about the use of Internet for communication with students in Trkman and Baloh (2002b).). During and after the course all instructors can be reached by e-mail for additional questions, explanations or clarifications. The used examples are structured and explained in such a way that they are straightforwardly understandable for the students and as close to their current interests as possible without endangering the other subgoals. Based on authors' experience from previous years, a special reference book for this course was written (Baloh, \& Vrecar, 2001) that also includes a CD-ROM with all examples and solutions. Hence, students can easily repeat 
exercises performed at the labs at home and/or after the end of the course in case they encounter a similar problem.

Noticeably, a considerable amount of effort is still needed in order to achieve the other three subgoals, though we try to eliminate any excess or unnecessary effort.

In order to better understand the success of our efforts, a survey was carried out at the end of the last three academic years. The survey was implemented as a questionnaire published on the World Wide Web and at the end of the course students were asked to fill it out. An instructor was present to help those that were still unfamiliar with the WWW, although the majority of students had no problems. In total 458 students took part in the survey out of the approximately 650 that attended classes at the University program. Most statistical data mentioned in this paper come from this survey; complete summarized results of the survey - after the survey they were available to participating students as well - can be found in (Introduction to information systems, 2001).

The purpose of the survey was two-fold: firstly, to identify the main characteristics of prior students' knowledge, experience and interest; secondly, to find more about their attitude and interests toward computers. The important results are presented in the continuation of this paper.

The results show that $97 \%$ of the students already have a computer at home and use it regularly. However, most of them use it only for basic tasks such as text editing and surfing the WWW. As a majority is familiar with World Wide Web and e-mail use, it is obvious that Internet can be and is used as a very efficient medium for communication with students. (97\% of the students found the information published on the home page of the course either useful or very useful) Also, we can conclude that the efforts invested in preparation and execution of those courses paid off; $94 \%$ of the students found the labs useful or very useful. This is a remarkable achievement considering, firstly, the fact that our students were business students, whose primary interests do not lie in the field of computers and information technology, and secondly, considering the fact that labs are compulsory.

In addition, $73 \%$ of students found the difficulty of those courses to be exactly right, with an additional $24 \%$ who found it either slightly too high or slightly too low. Only the remaining $3 \%$ found it much too high or much too low. Once again, we consider this as a fine achievement, especially when considering diverse backgrounds of students.

The survey confirmed the claims we made before: the use of the model guidelines for computers lab lectures at the Faculty of Economics resulted in a well-structured course that offers interesting, relevant topics and also equips students for further learning without unnecessary excess efforts. This was also welcomed by the students who recognize the effort invested by the instructors and respond well to it.

\section{Conclusion}

The model presented in the paper can serve every educator as a tool when considering changes in the way he or she teaches a certain topic. It can be used to establish which of the subgoals mentioned in the model is influenced by every change. Since the main model proposed is quite broadly set, it can be used in various fields and levels of formal or informal education.

As the importance of computer literacy education is increasing the model was applied to this field. We have shown the general guidelines that should be followed in it and the application of the model for computer literacy education at the University level. The presented case study of the Faculty of Economics, Ljubljana showed that this can indeed lead to improved results of education and is also perceived as such by the students. 
Further research and work on this model could include its application to various levels and fields of education as well as the refinement of instruments for evaluation, that is, measurement of the achievement of each of the four subgoals.

Obviously, the model in this paper is not a panacea for problems connected with education. Any learning requires an active involvement from students, teachers and others involved in it. As already written, every education is doomed to fail without an involved and motivated teacher who knows what s/he is trying to achieve and how s/he is going to achieve that.

\section{Acknowledgment}

We would like to thank four anonymous referees at the INSITE 2003 conference for their thorough review and helpful comments and suggestions, which helped us in improving our paper.

\section{References}

Baloh P., \& Trkman P. (2002). Model usposabljanja študentov Ekonomske fakultete za uporabo informacijske tehnologije (The model of enabling Faculty of Economics students for the use of Information Technology. Proceedings of Slovenian Informatics Conference 2002. Ljubljana: Slovenian Society Informatika, pp. 308-312. (in Slovene).

Baloh, P., \& Vrecar P. (2001). Ob prakticnih primerih skozi MS Office (With practical examples through MS Office). Velenje, Podplat. (in Slovene).

Bell, D. (1973). The Coming of post-industrial society. New York: Basic Books.

British and Irish Legal Education Technology Association. (1994). Setting the common minimum standards of computer competency for undergraduate lawyers. The Law Technology Journal, 3 (2).

Bradley, C., \& Oliver M. (2002). The evolution of pedagogic models for work-based learning within a virtual university. Computers \& Education, 38, 37-52.

Burton-Jones, A. (2001). The knowledge supply model: A framework for developing education and training in the new economy. Education \& Training, 43, 225-232.

Candy, P. (2000). Knowledge navigators and lifelong learners: Producing graduates for the information society. Higher Education Research \& Development, 19 (3), 261-277.

Collis, B. (1998). New didactics for university instruction: Why and how? Computers \& Education, 31, 373-393.

Drew, S. (1998). Key skills in higher education: Background and rationale. SEDA Special no. 6. Birmingham: Seda Publications.

Drucker, P. (2001). The essential Drucker. Oxford, UK: Butterworh-Heinemann.

Gerlic, I. (2001). Sodobna informacijska tehnologija v slovenskem izobraževalnem sistemu - stanje in trendi (Information technology in Slovenian educational system - current situation and trends). Organizacija, 34 (8), 484-492. (in Slovene).

Hawkey, R. (2002). The lifelong learning game: Season ticket or free transfer? Computers \& Education, 38, 5-20.

Hughes, L.R., Ginnett C.R., \& Curphy J.G. (1999). Leadership: Enhancing the lessons of experience. 3rd International Edition. Singapore: Irwin/McGraw-Hill.

Introduction to information systems. (2001). Results of the survey at Faculty of Economics, University of Ljubljana. Available online at http://www.ef.uni-lj.si/predmeti/infol/surveyresults.html

Johannessen, J-A., Olaisen, J., \& Olsen, B. (2001). Mismanagement of tacit knowledge: The importance of tacit knowledge, the danger of information technology, and what to do about it. International Journal of Information Management, 21,320

Krapež, A. (1999). Stanje in problematika informatike v srednjih šolah (Situation and problems of information systems in secondary schools). Organizacija, 31 (9), 434-436. (in Slovene).

Krapež, A., Rajkovic V, Batagelj V, \& Wechtersbach R. (2001). Razvoj predmeta racunalništvo in informatika v osnovni in srednji šoli. The development of computer education in primary and middle schools). Proceedings of Slovenian Informatics Conference 2001. Ljubljana: edited by Slovenian Society Informatika, 353-359. (in Slovene). 
Luft, P., \& Tiene, D. (1997). Using instructional design principles to develop Web-based teaching units. Paper presented at TELED 97, Austin, TX. Available online at http://www.educ.kent.edu/ pluft/instr_des/

McAvinia, C., \& Oliver M. (2002). "But my subject's different": A web-based approach to supporting disciplinary lifelong learning skills. Computers \& Education, 38, 209-220.

McIntyre, D., \& Wolff, F. (1998). An experiment with WWW interactive learning in university education. Computers \& Education, 31, 255-264.

Moonen, J. (1994). How to do more with less? Interactive multimedia in university education: Designing for change in teaching and learning, 155-163. Amsterdam: Elsevier.

Norman, N. (1997). Communication technologies and education: Lessons in the potential of innovation. Journal of Advanced Learning Technologies, 5(3), 43-53.

Rajkovic, V. (1998). Program Racunalniško opismenjevanje v osnovnih in srednjih šolah (Computer Literacy Program in primary and secondary schools). Ljubljana: Zavod RS za šolstvo, Vzgoja za medije in z mediji. (in Slovene).

Toplišek, J. (1997). Informatika in informacijska tehnologija v študijskih programih pravnih fakultet (Information systems and information technology in educational programmes of faculties of law). Pravna Praksa 97(1), 1-27. (in Slovene).

Trkman, P., \& Baloh, P. (2002a). Effective teaching of use of information technology for business students. Computers in Education, proceedings of the conference. Opatija: MIPRO.

Trkman, P., \& Baloh, P. (2002b). Uporaba interneta pri komuniciranju s študenti poslovno informacijskih predmetov v 1. letniku Ekonomske fakultete (The use of Internet for communication with the students of Management Information Systems in first grade of Faculty of Economics). Proceedings of 7th International Conference on Education MIRK 2002. Ljubljana: Zavod Republike Slovenije za šolstvo: Zavod za projektno in raziskovalno delo na omrežju Internet (MIRK), 2002. (in Slovene)

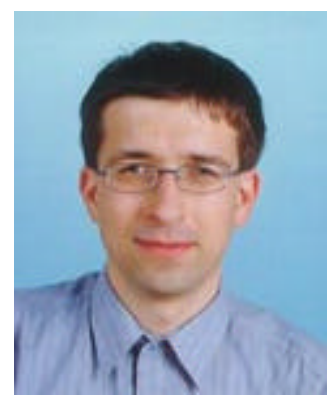

\section{Biography}

Peter Trkman, M. Sc., is an assistant lecturer for Information Management at the Faculty of Economics, University of Ljubljana, Slovenia. In the past seven years he taught computer lab lectures for first-year students at the Faculty and written several papers about theoretical and practical considerations of computer literacy education. Additionally, he has published research papers on other topics such as operations research, strategic use of information technology and liberalization of telecommunications.

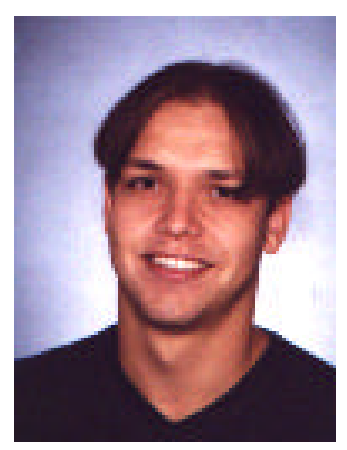

Peter Baloh, M. Sc., is an assistant lecturer for Information Management at the Ljubljana University, the Faculty of Economics. His pedagogical work in the past seven years was mainly teaching computer lab lectures for business students. His main research interest is concentrated around the question of influence of conte mporary Information and Communication Technologies and Information Management as a whole on (better) business performance. Topics of interest in view of that include business informatization, information audits, business process modeling, stochastic financial modeling, constrained optimization, and education in ICT field. 